\title{
The formation and dissolution of inter-firm linkages in lengthy and stable networks in clusters.
}

\author{
F. Xavier Molina-Morales, Universitat Jaume I de Castellò \\ José A. Belso-Martínez, Universidad Miguel Hernández \\ Francisco Más-Verdú, Universitat Politécnica de Valencia \\ Luis Martínez-Cháfer, Universitat Jaume I de Castelló \\ This Version: February 2014 (Preprint) $^{1}$
}

The authors acknowledge financial support provided by the Spanish Ministry of Economy and Competitiveness (Research Project Number ECO2012-32663 and Research Project Number ECO2010-2055). The authors alone are responsible for all limitations and errors that may relate to this paper. Send any correspondence to F. Xavier Molina-Morales, Universitat Jaume I de Castellò, Departament de Organitzaciò d'Empreses i Marketing, Avinguda de Vicent Sos Baynat, s/n, 12071, Castelló de la Plana, Spain; Telephone: +34 964728000 (molina@emp.uji.es); José A. BelsoMartínez, Universidad Miguel Hernández, Departmento de Estudios Económicos y Financieros, Avenida de la Universidad s/n, 32020, Elche, Spain; Telephone: +34966 658918 (jbelso@umh.es); Francisco Más-Verdú, Universitat Politecnica de Valencia, Departamento de Economía y Ciencias Sociales, Camino de Vera s/n, 46022, Valencia, Spain; Telephone: +34 963877479 (fmas@upvnet.upv.es). Luis Martínez-Cháfer, Universitat Jaume I, Departament de Organitzaciò d'Empreses i Marketing, Avinguda de Vicent Sos Baynat, s/n, 12071, Castelló de la Plana, Spain; Telephone: +34 96472 8000 (chafer@emp.uji.es)

\footnotetext{
${ }^{1}$ Final journal version available here: http://www.sciencedirect.com/science/article/pii/S014829631500065X
} 


\begin{abstract}
Firms aspire to take advantage of technical and business networks through interorganizational interactions in order to improve performance. Consequently, researchers are increasingly attracted by the dynamics and implications of network formation at both local and global levels.

From another perspective, authors have abandoned a monotonic effect and simplistic approach to proximity, as it emerges as a complex and multidimensional notion.

Using data from a foodstuffs cluster located in the Valencia region (Spain) and advanced econometric methods, this paper aims to shed light on the detrimental effects and complementarities that may arise among the proximity dimensions. After controlling for network endogenous forces and firm characteristics, our findings reveal the effect of proximity dimensions on the creation of linkages in advanced stages of the cluster life cycle, in addition to the interactions among them.
\end{abstract}

Key words: clusters, networks, ERGM, Social capital, proximity 


\section{Introduction}

Over the last decade a growing amount of attention has been paid to identifying key factors for the creation and development of successful collaborations between organizations. Such interest relies on the critical role played by these collaborative relationships in generating innovations, particularly through common learning and knowledge spillovers (e.g., Asheim and Gertler, 2007).

However, despite scholars' efforts to unravel the patterns of the formation of inter-organizational relationships, the genesis and dynamics of network structures still demands much more additional work (Ahuja et al., 2012). Particularly, while endogenous mechanisms leading to network development have already received considerable attention (Rivera et al., 2010), studies accounting for the attributes of network units are not so common and still need to be addressed properly. Particularly, little is known about the development of relational architectures and how the characteristics of ties change over time.

Studies on industrial clusters that adopt an evolutionary approach have proliferated over the last decade (Giuliani and Bell, 2005; Boschma and Ter Wal, 2007; Morrison and Rabellotti, 2009; among others). Industrial clusters can be considered networks, social in nature (Ter Wal and Boschma, 2009), comprising different stakeholders who interact, evolve and contribute to the performance of a specific geographical context. The particular nature of these networks makes them appropriate structures for a refined analysis of interactions at the firm level.

The evolutionary approach elucidates the prerequisites required to develop successful collaborations, thereby overcoming the so-called "localist trap that traditionally emphasized the role played by co-location and territorialized dynamics" (Gertler, 2003). This view is mainly based on the seminal contribution by Boschma (2005) and focuses on five different types of proximity suggested by the author: cognitive, social, organizational, institutional, and geographical. These proximities are closely related (Boschma and Frenken, 2010; Mattes, 2012; Ben Lataifa and Rabeau, 2013) and co-evolve over time (Broekel, 2012). 
Some researchers have recently conciliated the influence of structural mechanisms and the relevance of node attributes in the evolution of relationships (Ter Wal, 2013; Balland et al., 2013, among others). However, many aspects related to the dynamics of network formation still remain largely unexplored.

We aim to help cover the research gaps by exploring the contribution of the structural tendencies of networks and proximity dimensions to knowledge sharing and linkages. To do so, we use data from a sample of companies from a mature foodstuff cluster located in the Valencia region (Spain). To accomplish this task, an exponential random graph model (ERGM) was developed and tested using data from 36 nougat manufacturers and their suppliers obtained by means of a survey carried out in 2011.

The remainder of the paper is structured as follows. Section 2 gives an overview of the theoretical framework and the hypotheses. Section 3 describes the main traits of the selected industrial cluster. Section 4 presents methodological aspects, econometrics, and results. Finally, Section 5 concludes the paper by highlighting key findings and suggesting implications.

\section{Theoretical Background}

\subsection{The proximity approach}

Proximity is a fuzzy concept that demands a complex approach (Markussen, 1999). Particularly, the contributions of the so-called French School (e.g. Torre and Rallet, 2005) stressed the need for a multidimensional perspective to complete an accurate assessment of the effects of geographical proximity (Autant-Bernard et al., 2007).

\section{Cognitive proximity}

Knowledge spillovers are not inherent to closely located firms (Boschma and Iammarino, 2009). Interaction among units is necessarily the starting point for learning and knowledge sharing to take place. However, the existence of a common interpretative scheme determines the fruitfulness of these processes. Firms may reveal cognitive constraints that make it impossible for them to act in an optimal way. The cognitive dimension describes the initial ability of actors to communicate meaningfully 
and generate new knowledge before the learning process started, which essentially implies sharing common and complementary skills and knowledge.

\section{Organizational proximity}

Organizational proximity is defined as the extent to which relations are shared in an organizational arrangement, and is based on the notions of autonomy and control. The more control and possibilities of regulating interactions there are, the higher organizational proximity is. Conversely, the more autonomy induced by the link, the less organizational proximity exists. Organizational closeness usually appears through prior collaboration experiences (D'Este et al., 2012), between firms within the same group (Balland, 2012) or in long-term subcontracting relationships. Hierarchical interconnection between firms fosters knowledge sharing and common learning, since reduces uncertainty and limits the risk of opportunism.

\section{Social proximity}

Social embeddedness refers to the extent to which actors are connected to other alters via the linkages of a social network, or the extent to which human behavior takes place within a web of social attachments such as friendship, kinship, and past experiences. Following this path, social proximity represents strongly embedded social relations between actors at the micro-level involving trust (Boschma, 2005). The degree of social closeness is of crucial importance to explain economic outcomes (Granovetter, 1985), because trust-based ties foster knowledge transfers and common learning practices.

In a dynamic process over time Social links engender different levels of trust and moderate the risk of opportunistic behaviors and the appropriation of rents (Dettam and Brenner, 2010). In this vein, geographical propinquity fosters the strength of social ties through frequent meetings and building trust, but it is only a need in the initial stages (Dettman and Brenner, 2010) and thereafter is maintained by temporary geographical co-location (Torre, 2008; Ramirez-Pasillas, 2010). 


\section{Institutional proximity}

Following Edquist and Johnson (1997), institutions are constituted by sets of common habits, routines, recognized practices, rules and law that regulate human and inter-organizational interactions. Hard institutional factors (laws and rules) are thereby equally as important as soft ones (norms, values and routines). Therefore, institutional proximity is a complex combination of hard and soft macro-level factors (Xu and Shenkar, 2002) that provides a framework of stability and shapes cooperative behaviors. Boschma (2005) highlights the interconnection of both organizational and institutional forms of proximity, as the ways intra- and inter-organizational relations are governed are embedded in institutional settings. Additionally, he also points out the potential existence of an inverse relationship between the importance of geographical proximity and institutional proximity for successful learning and collaboration.

\section{Geographical proximity}

Given the widespread consensus about the localized nature of knowledge production and spillovers (Audretsch and Feldman, 1996), innovation activities appear to be an exception to the so-called "death of distance" induced by the widespread adoption of modern ICT (Morgan, 2004). On the other hand, a number of authors have questioned the theoretical importance of the spatial or physical distance between actors for collaboration and knowledge exchange (Breschi and Lissoni, 2001; Gertler, 2003, Boschma, 2005). However, from an empirical viewpoint, evidence does not support the decline of the spatial proximity effect (Frenken et al., 2010).

Despite the above-mentioned positive effects of geographical propinquity on learning, the most relevant value of geographical proximity is its role as a moderator, which it plays by strengthening other forms of proximity (Broekel and Boschma, 2011), probably through an indirect impact. In fact, geographical proximity promotes, among other things, the formation/evolution of institutions, embeddedness and trust, and/or cognitive closeness. Furthermore, under certain circumstances, these four proximity dimensions may also function as substitutes for physical proximity (Boschma, 2005). For instance, spatial proximity may help to overcome institutional (Ponds et al., 2007) or cognitive distance (Singh, 2005), and so on. 


\subsection{Dynamics of cluster}

Similarly to what happens to the industry life cycle, in the stages of the emergence of a cluster there are just a few firms, which is then followed by growth with an increasing number of firms and employees, and finally decline, where the number of firms and employees decreases.

We are particularly interested in the process of decline, especially in finding out what internal and external causes lie at the core of these processes. According to authors, cluster decline can be induced by too much embeddedness of the institutional context and lock-in into an ineffective systemic framework that may damage learning or creativity; or cognitive lock-in, which means that local firms share a common view which restricts understandings and novel responses to potential situations (Belussi, 2006; Grabher, 1993, among others).

Evidence from Lagnevik et al. (2003) suggested that the European food clusters had been in the advanced stages of the life cycle (mature-decline or renaissance) since the beginning of the last decade, when the industry faced the surge of the new technologies, many products became obsolete and new actors invaded the competitive landscape. We expect development of the cluster life cycle to be, at least partially, explained by the evolution of some of the dimensions of proximity.

\section{Hypotheses}

Cognitive proximity entails both opportunities and threats in the process of learning. Firms need to share common and complementary skills and a knowledge base to be able to interact with each other successfully. Therefore, cognitive proximity eases collaboration as it facilitates valuable outcomes thanks to continuous communication and absorption. However, lengthy cooperation in stable networks in the maturity stage may reduce diversity of inter-firm knowledge exchanges, and progressively diminishes the opportunities for learning (Wuyts et al., 2005). Consequently, as networking takes time and efforts, partners avoid or dissolve redundant linkages that appear unlikely to produce benefits. Organizations which are cognitively very close can be expected to feel 
discouraged to engage new links with them and with other actors. Consequently, it can be hypothesized:

$\mathrm{H}_{1}$ : Cognitive proximity is negatively related to the creation of linkages in advanced stages of the cluster life cycle.

Institutions consist of both informal constraints, customs, traditions or codes of conduct, and formal rules, constitutions, laws or rights (North, 1991). Institutions are stable designs for a chronically repeated activity, bearing the characteristic of path dependency and cumulative causation. As a cluster grows, a set of rules and norms that legitimate and standardize behaviors and govern transactions emerge endogenously. While institutions initially stimulate the development of the agglomeration, they may turn out to foster inertia that obstructs awareness and the appearance of different opportunities during the maturity (decline) stage of long-established systems (Grabher, 1993).

Such institutional sclerosis arises due to a "competency trap", which refers to individual organizations' competence to make specific achievements as well as the competence of institutions to manipulate the relationships between actors so to achieve successful interactions. It also includes the vested interests that emerge in the formation process of institutional setup, which might oppose necessary changes that undermine the position of local firms (Boschma, 2005). In line with our previous hypotheses, it can be expected that:

$\mathrm{H}_{2}$ : Institutional proximity is negatively related to the creation of linkages in advanced stages of the cluster life cycle.

Firms tend to form or reactivate ties in order to solve problems of network redundancy. Local embedding that is too long-lasting derives into an excess of cognitive proximity and redundancies, but it also generates familiarity and trust (Gulati, 1995). Trust raises cooperative behavior, facilitates knowledge exchange and makes knowledge transfers more effective (Singh, 2005). For instance, relationships become more frequent and valued when the actors involved eventually trust one another. This trusting atmosphere emerges as the result of face-to-face interactions that are inherent to geographical proximity and leads to knowledge sharing and cooperative behavior 
(Asheim and Gertler, 2007). Recent research highlights how both social and geographical proximities follow a similar path as the network matures (Ter Wal, 2013).

$\mathrm{H}_{3}$ : Both geographical and social proximity favor the creation of linkages in advanced stages of the cluster life cycle.

Institutional and organizational proximities are related. Institutional thickness is based on a set of common representations, models and rules at the macro-level. Following Talbot (2007), organizational proximity may be considered a form of institutional proximity. Organizations (like firms or even formal partnerships) create a common space with their own operational rules and routines, as well as their own governance structure observable to all members (Bazzoli and Dutraive, 2002). Ben Lataifa and Rabeau (2013) study this relatedness by focusing on close linkages between organizational and institutional forms of proximity.

On the other hand, advanced stages of the cluster life-cycle may not only present an unsuitable institutional framework for network formation, but also an excess of cognitive proximity causing overlaps and unplanned spillovers when firms compete in the same market with similar products (Vicente et al., 2007). Under these circumstances, firms will avoid these knowledge losses and harmful behaviors through a self-designed governance framework favored by cognitive commonalities. When norms and rules do not work at the macro level, firms tend to create an institutional context at the micro level. When collaborators develop a similar view of the business or the way to do things, then it is very easy to become organizationally close, thus avoiding the need to foster new ties in the network. Finally, an excess of institutional proximity and an excess of cognitive proximity favor organizational proximity and consequently boost the creation of new relationships in the network.

$\mathrm{H}_{4}$ : In advanced stages of the cluster life-cycle, high institutional and cognitive proximities favor organizational proximity, enhancing its role in network formation. 


\section{The empirical context}

This research has drawn on a sample of the firms belonging to the Spanish chocolate and confectionery industry. Particularly, the production of Spanish traditional nougats and other Christmas candies in Xixona (Valencia region) represents a paradigmatic case.

Recently, the ISTAT methodology allowed Boix and Galletto (2006) to identify this geographical area as an industrial one. However controversy exists about different systemic aspects. March et al. (2007) specifically highlighted not only those related to cohesion and cooperation dynamics, which should be particularly mentioned, but also the prevalence of heterogeneous behaviors on key strategic outlines delineating a fragmented business community in terms of strategic and competitive advantages (especially large corporations vis-à-vis SMEs). Consistently, it seems that nougat manufacturers benefit from location, but some deficits hamper the achievement of many technical and commercial synergies.

\section{The study setting}

\subsection{The questionnaire}

Data for this research was collected in Xixona during the second half of 2011. In a preliminary stage, face-to-face interviews with key manufacturers and local supporting organizations were carried out to gather primary data about multiple aspects of the industry and the cluster. Using insights from the interviews and the literature, we designed a detailed questionnaire dealing with aspects such as the firm's characteristics, innovation practices, inter-organizational relationships, and performance. Once it had been pre-tested, we submitted our tool to the universe of manufacturers located inside the cluster boundaries.

\subsection{Data collection}

All 36 local manufacturers and suppliers obtained from TDC (the local nougat trade association) and the Regulatory Council were surveyed, thus enabling them to provide information about their local relationships. Peer debriefing confirmed that just a few artisans (usually self-employed) were missing and all relevant actors were considered. In the end, 24 nougat and Christmas candy manufacturers and 12 suppliers 
cooperated, yielding an appropriate response rate for a whole-network approach (Wasserman and Faust, 1994).

To collect network data, we presented respondents with a roster of the names of all 36 firms, and asked them to indicate from which of firms on the list did you regularly ask for technical information over the last three years. Answers rated from 0 to 3 according to the existence and relevance of the connections. This "roster-recall" method reduces selectivity bias in the answers due to memory effects.

$<$ Insert Table 1 about here $>$

Table 1 presents descriptive statistics on firm level characteristics, such as size, decade of creation, legal structure or international operations. Additionally, membership and main business activities are also reported.

\subsection{Variables}

\section{Dependent variable}

Relational data allowed the creation of a directed square network matrix, which served as the dependent variable. Each column $i$ and each row $j$ represents a firm, and the cell entries are the value that firm $i$ perceives about its relationship with firm $j$. Note that this matrix is not symmetric as the value perceived by firm $i$ is not necessarily the same as the value perceived by firm $j$.

Due to our estimating procedure and software, the dependent variable must be in binary form. Therefore, we collapse the perceived value into a dummy variable, coded 1 for rates 2 and 3, and 0 otherwise. By doing so, we ensure the existence of relevant interactions, as the actual threshold at which a firm is considered to interact relevantly may vary greatly.

\section{Explanatory variables}

The proximity insights lead us to expect that closeness between firms would affect network dynamics. To measure this effect, we include five dyadic covariates. Each dyadic covariate is a symmetric matrix with size $36 \times 36$ that takes a specific value 
for every pair of firms. In the geographical proximity covariate, values in the matrix reflect the physical distance between the two firms. NACE codes allow the creation of the cognitive proximity covariate. We assign value 1 if the firms share the same four NACE digits, and give value 0 otherwise. The third dyadic covariate captures institutional proximity based on firm's legal status. Cells in this matrix get value 1 when firms have the same legal status, and value 0 otherwise. In order to account for organizational proximity, we build a new matrix which measures whether firms belong to the same group. We code 1 if firms belong to the same group, and code 0 otherwise. Information from TDC allows us to configure a social proximity covariate based on the existence of familiar relationships between firms' owners. Cells take value 1 if familiar relationships exist, and take value 0 otherwise.

We also applied indicators to test whether firm characteristics influence the creation of ties. To this end, the following individual covariates or attributes are added: size (square root of total sales), age (square root of years since creation), absorptive capacity (code 0 when the firm does not employ workers holding a university degree, code 1 otherwise) and supplier (code 0 when the firm is a nougat or candy manufacturer, code 1 otherwise). For different values of each individual characteristic, we test whether the firm is more likely to seek advice (ego) or if it is more prone to be asked for counsel (alter), and the influence of the absolute difference on a particular attribute.

Finally, we control for a number of variables that will tap into the knowledge network structure. These parameters reflect "endogenous forces", and tell whether interactions occur more or less often than expected by chance. Following well-known specifications (Hunter, 2007), we selected the mutual parameter that evaluates reciprocity, or the inclination to give back in a cooperative manner (e.g. tendency to A$>\mathrm{B}$ given that $\mathrm{B}->\mathrm{A})$. The cyclic closure term (CTriple) that reflects a tendency towards generalized reciprocity amongst organizations (e.g. triangle $\mathrm{A}->\mathrm{B}, \mathrm{B}->\mathrm{C}$ and $\mathrm{C}->\mathrm{A}$ ). Additionally, we use the geometrically weighted parameter for the distributions of indegree (GWIDegree) and another for outdegree (GWODegree). The first indicates the distribution of tie frequency reported to firms in the network, while the second reflects the distribution of outgoing ties reported by respondents. Finally, geometrically weighted edge-wise shared partnerships (GWESP) evaluates the transitivity in the 
network and is considered an indicator of cohesion. Essentially, transitivity refers to the fulfillment of the "friend of my friend is my friend" paradigm. In other words, if two firms share a common network partner, they tend to become partners (e.g. A- $>$ C and B$>\mathrm{C}$, then $\mathrm{A}->\mathrm{B}$ or $\mathrm{B}->\mathrm{A})$.

\subsection{Statistical analysis and results}

To test the hypotheses established, we applied a Exponential Random Graph Model approach (ERGM). These are probability models that represent the generative process of tie formation and investigate the structure within a complete social network. In our case, we look at inter-organizational linkages within a technical network, where a link represents one firm asking technical advice to another firm. These network relations do not just form randomly but have a certain underlying pattern. With ERGM it is possible to examine and empirically test these structural patterns, and ask for example whether changes in partners are consequence of firm's position within the network.

The rationale underlying our model is that the observed technical network is just one realization out of all potential realizations, and might be observed simply by chance. To see to what extent the observed technical network diverges from a network obtained by chance, a number of random networks are generated through Markov chain Monte Carlo maximum likelihood estimation. The simulated network is compared to the observed network in terms of parameters. This procedure is repeated until the simulated network provides a good representation of the real network.

As recommended for ERGM, we add variables in consecutive blocks to test their relative contributions. The baseline model includes the individual covariates or firmlevel attributes. The intermediate model incorporates the dyadic covariates, while the endogenous forces join the model in the final stage. As Goodreau (2007) indicates, this procedure also allows for an accurate assessment of the role of the network forces above and beyond what firm characteristics and relational attributes explain. Following Hunter et al. (2008), statistical measures of model fit were discarded due to data interdependency. Instead, goodness-of-fit (GOF) plots comparing the observed network with a set of simulated networks based on certain features were checked. 
As per the final model in Table 2, results are in line with our expectations. Both cognitive and institutional proximities exercise a negative significant effect on the creation of linkages, at the $\mathrm{p}$-value $<0.01$ and $\mathrm{p}$-value $<0.10$ respectively. Therefore, $\mathrm{H}_{1}$ and $\mathrm{H}_{2}$ are supported. Conversely, the geographical and social dimensions enhance linkages. The significant sign obtained at p-value 0.01 and 0.1 respectively, endorse $\mathrm{H}_{3}$. In the same vein, organizational proximity also fosters common learning and knowledge sharing within cluster boundaries ( $\mathrm{p}$-value $<0.01$ ).

Control variables provide interesting insights into the selective nature of the network formation process. While age fosters the creation of linkages at $p$-value $<0.10$, the absolute difference between partners generates the opposite effect ( $p$-value $<0.01$ ). This evidence indicates that the advice dynamics is shaped by the status effect. Wellknown firms have more linkages, but connections are less likely to occur between older and recently created units. In addition, just the out-effect of the absorptive capacity attribute achieves a negative significant effect $(p$-value $<0.01)$, indicating that firms showing strong knowledge bases are more selective and less prone to ask for advice.

The sensitivity diagnosis corroborates the robustness of our results. The autocorrelation coefficients among various intervals are close to 0 , with the exception of the initial one, which always takes the value of 1 . Moreover, Gewerke statistics, which are relatively comparable to a $\mathrm{Z}$ statistic, give no significant return for a $\mathrm{p}$-value $<0.10$. Despite the improvement in measures of model fit such as the AIC and BIC, commonly used to compare nested statistical models like these, we discard them as these measures rely on independent data (Hunter et al., 2008). Instead, parameter traces and goodnessof-fit plots comparing observed network characteristics with those of simulated networks based on each model were used. Generally speaking the model is not only stable and converges, but is also characterized by reasonable horizontal traces. Although detailed observation of the different plots of network parameters reveals some disparities, note that our main interest lies in testing the hypotheses related to actor traits.

Further statistical analysis was conducted to test to what extent cognitive and institutional proximity may favour the emergence of organisational proximity in 
advanced stages of the cluster life cycle. The quadratic assignment procedure, a nonparametric technique frequently applied to relational data, permits the regression of a dependent matrix on one or more independent matrices. The dependent variable is the organisational proximity, while the independent variables are the other proximity dimensions and a matrix reflecting age difference of the firms. Correlations between independent variables ranged from 0.01 to 0.05 , indicating no problems of multicollinearity.

$<$ Insert Table 3 about here $>$

Table 3 displays QAP regression results for our knowledge network. Goodness of fit values reveal that the model offers a good explanation for the phenomenon analyzed. Results obtained confirm our expectations on the reinforcing role of institutional and cognitive proximities on the organizational proximity. Both forms of proximity are found to enhance the organizational dimension. Therefore, taking into consideration the outcome from the ERGM, which revealed the positive effect exercised by organizational proximity on the likelihood of being linked to other firms, we can confirm $\mathrm{H}_{4}$.

\section{Discussion and conclusion}

The present study focuses on the dynamics of network formation in mature and declining clusters, using ERGM and data collected in a foodstuff cluster in Spain. The baseline model explored the propensity of firms to establish and receive ties based on firm-level attributes, whereas the intermediate model also controlled for the influence of dyadic covariates (proximity dimensions).

As expected, empirical findings confirm the idea that proximity dimensions interrelate and influence the dynamics of the technological knowledge network. Obviously this endorses the idea that firms benefit from sharing information, as it may allow joint problem-solving and common innovation practices. Moreover, the potentially negative effects of an excess of proximity are another important factor. In the network studied here, too much cognitive and institutional proximity degrades the formation of intra-cluster linkages. Firms are aware of the high cost of networking, and 
hence are careful when choosing their technological partners, namely those whose cognitive maps are complementary rather than redundant. On the other hand, the lack of suitable norms and rules undermines the genesis of new linkages and fosters the dissolution of former partnerships. An obsolete institutional framework generates dysfunctions in business relationships, hindering cooperation and knowledge transfers.

From another perspective, two or more forms of proximity seem necessary to sustain network formation. In view of our findings, social, organizational and geographical closeness may take over from other forms of proximity that were formerly crucial for building relationships but, have now become barriers for cooperation. Additionally, what seems to be outstandingly interesting is how excess of proximity in lengthy interactions may exert not just a negative influence in the creation of linkages, but also foster the impact of related proximity dimensions. The fine combination of our models evidences that both institutional and cognitive proximity may contribute to the emergence of organizational proximity.

Another conclusion suggested by our results refers to the interactions between the dimensions of proximity. Findings showed that two or more forms of proximity may complement each other. In fact, other dimensions of proximity offset the detrimental effects caused by certain forms of proximity.

These findings are not free from certain limitations. Foremost, they derive from informants' perceptions and self-reports of previous behaviors. As is common in similar procedures, memory errors and omissions may exist. Undoubtedly, we make decisions to mitigate these potential deficiencies, but relationships that neither party reported or over/under evaluation of past experiences can occur. Nonetheless, relying on informants' recall was necessary in order to obtain the information about the complete intra-cluster networks, assuming a trade-off between robustness and completeness. 


\section{References}

Asheim, B.T., and M.S. Gertler (2007). The Geography of Innovation. In J. Fagerberg,, D. C. Mowery \& R.R. Nelson (Eds.), The Oxford Handbook of Innovation. Oxford: Oxford University Press (291-317).

Ahuja, G., G. Soda, and A. Zaheer (2012). The genesis and dynamics of organizational networks. Organization Science, 23, 434-448.

Audretsch, D., and P. Feldman (1996). R\&D spillovers and the geography of innovation and production. American Economic Review, 86(3), 630-40.

Autant-Bernard, C., J. Mairesse, and N. Massard (2007). Spatial knowledge diffusion through collaborative networks. Papers in Regional Science, 86, 495-519.

Balland, P. (2012). Proximity and the Evolution of Collaboration Networks: Evidence from Research and Development Projects within the Global Navigation Satellite System (GNSS) Industry. Regional Studies, 46(6), 741-756.

Balland, P., M. de Vaan and R. Boschma (2013). The dynamics of interfirm networks along the industry life cycle: The case of the global video game industry, 19872007. Journal of Economic Geography, 13(5), 741-765.

Bazzoli L. and V. Dutraive (2002). L'entreprise comme organisation et comme institution. Un regard à partir de l'institutionnalisme de J. R. Commons. Economie et Institutions, 1(2), 4-46.

Belussi, F. (2006). In search of a theory of industrial districts and clusters. In B. Asheim, P. Cooke \& R. Martin (Eds.) Clusters in Regional Development. London: Routledge (50-68).

Ben Lataifa, S, and Y. Rabeau (2013). Too close too collaborate? How geographical proximity could impede entrepreneurship and innovation. Journal of Business Research, http://dx.doi.org/10.1016/j.jburses.2013.02.033. 
Boix, R., and V. Galletto (2006). Sistemas locales de trabajo y distritos Industriales marshallianos en España. Economía Industrial, 359, 165-84.

Boschma, R. (2005). Proximity and innovation: A critical assessment. Regional Studies, $39,61-74$.

Boschma, R. and S. Iammarino (2009). Related Variety, Trade Linkages and Regional Growth. Economic Geography, 85(3), 289-311

Boschma, R. and K. Frenken (2010). The spatial evolution of innovation networks. A proximity perspective. In R. Boschma \& R. Martin (Eds.), Handbook on Evolutionary Economic Geography. Cheltenham: Edward Elgar (120-138).

Boschma, R. and A. Ter Wal (2007). Knowledge networks and innovative performance in an industrial district: the case of a footwear district in the South of Italy. Industry and Innovation, 14, 177-199.

Breschi S., and F. Lissoni (2001). Knowledge Spillovers and Local Innovation Systems: A Critical Survey. Industrial and Corporate Change, 10(4), 975-1005.

Broekel, T. (2012). The co-evolution of proximities - a network level study. Papers in Evolutionary Economic Geography, 1217.

Broekel, T., and R. Boschma (2012). Knowledge networks in the Dutch aviation industry: the proximity paradox. Journal of Economic Geography, 12, 409-433.

D’Este, P., F. Guy, and S. Iammarino (2012). Shaping the formation of universityindustry research collaborations: what type of proximity does really matter?. Journal of Economic Geography, doi:10.1093/jeg/lbs010

Dettmann A. and T. Brenner (2010). Proximity is a social process: a conceptual modification. Paper presented at the DRUID Winter PHD Conference 2010, Aalborg, January 21-23. 
Edquist, C. and B. Johnson (1997). Institutions and Organizations in Systems of Innovation. In C. Edquist (Ed.), Systems of Innovation: Technologies, Institutions and Organizations. London: Pinter Publishers (41-63).

Frenken, K., R. Ponds, and F. Van Oort (2010). The citation impact of research collaboration in science-based industries: A spatial-institutional analysis. Papers in Regional Science, 89, 351-371.

Gertler, M. (2003). Tacit knowledge and the economic geography of context, or the undefinable tacitness of being (there). Journal of Economic Geography, 3, 75-99.

Giuliani, E. and M. Bell (2005). The micro-determinants of meso-level learning and innovation: Evidence from a Chilean wine cluster. Research Policy, 34, 47-68.

Goodreau, S. (2007). Advances in exponential random Graph (p*) models applied to a large social network. Social Networks, 29, 231-248.

Grabher, G. (1993). The weakness of strong ties. The lock-in of regional development in the Ruhr area. In G. Grabher (Ed.) The Embedded Firm, London: Routledge (255-277).

Granovetter, M. (1985). Economic action and social structure: The problem of embeddedness. American Journal of Sociology, 91(3), 481-510.

Gulati, R. (1995). Familiarity breeds trust? The implications of repeated ties on contractual choice in alliances. Academy of Management Journal, 38, 85-112.

Hunter D. (2007). Curved exponential family models for social networks. Social Networks, 29, 216-30.

Hunter D., S. Goodreau, and M. Handcock (2008). Goodness of fit of social network models. Journal of the American Statistical Association, 103(481), 248-58. 
Lagnevik, M., I. Sjoholm, A. Lareke, and J. Ostberg (2003). The Dynamics of InnovationClusters: A Study of the Food Industry. Cheltenham: Edward Elgar.

March-Chordá, I., C. Adame-Sánchez, and A. Escrig-Tena (2007). Aplicación de un modelo de caracterización de la competitividad al sector de fabricación de turrón. Revista valenciana de economía y hacienda, 6, 111-138.

Markusen A. (1996). Sticky places in slippery space: a typology of industrial districts. Economic Geography, 72, 293-313.

Mattes, J. (2012). Dimensions of proximity and knowledge bases. Innovation between spatial and non-spatial factor. Regional Studies, 46(8), 1085-1099.

Morgan, K. (2004). The exaggerated death of geography: Learning, proximity and territorial innovation systems. Journal of Economic Geography, 4(1), 3-21

Morrison, A. and R. Rabellotti (2009). Knowledge and information networks in an Italian wine cluster. European Planning Studies, 17, 983-1006.

North, D. (1991). Institutions. Journal of Economic Perspectives, 5(1), 97-112.

Ponds, R., F. van Oort, and K. Frenken (2007). The geographical and institutional proximity of research collaboration. Papers in Regional Science, 86, 423-443.

Ramirez-Pasillas, M. (2010). International trade fairs as amplifiers of permanent and temporary proximities in clusters, Entrepreneurship and Regional Development, $22,155-187$

Rivera, M., S. Soderstrom and B. Uzzi (2010). Dynamics of dyads in social networks: Assortative, Relational and Proximity Mechanisms. Annual Review of Sociology, 36(1), 91-115.

Singh, J. (2005). Collaborative networks as determinants of knowledge diffusion patterns. Management Science, 51(5), 756-770. 
Talbot, D. (2007). Appropriability, proximity routines and innovation. Paper presented at the DRUID Conference. Copenhagen, Denmark, June 18 - 20

Ter Wal, A. (2013). The dynamics of the inventor network in German biotechnology: geographic proximity versus triadic closure, Journal of Economic Geography, doi: $10.1093 / \mathrm{jeg} / \mathrm{lbs} 063$

Ter Wal, A., and R. Boschma (2009). Applying social network analysis in economic geography: theoretical and methodological issues. Annals of Regional Science, 43, 739-756.

Torre, A. (2008). On the role played by temporary geographical proximity in knowledge transmission. Regional Studies, 42, 869-889.

Torre, A. and A. Rallet (2005). Proximity and Localization. Regional Studies, 39(1), 4759.

Vicente J., Y. Dalla Pria, and R. Suire (2007). The ambivalent role of mimetic behavior in proximity dynamics: evidence from the 'Silicon Sentier'. In J. Surinach, R. Navarro, E. Vayá (Eds.), Knowledge externalities, innovation clusters and regional development, Northampton: Edward Elgar (61-89).

Wasserman, S., and K. Faust (1994). Social Network Analysis: Methods and Applications. Cambridge: Cambridge University Press.

Wuyts, S., M. Colombo, S. Dutta and B. Nooteboom (2005) Empirical test of optimal cognitive distance. Journal of Economic Behaviour and Organization, 28, 277 302.

Xu, D., and O. Shenkar (2002). Institutional distance and the multinational Enterprise. Academy of Management Review, 27(4), 608-618. 
Table 1. Descriptive statistics of the sample

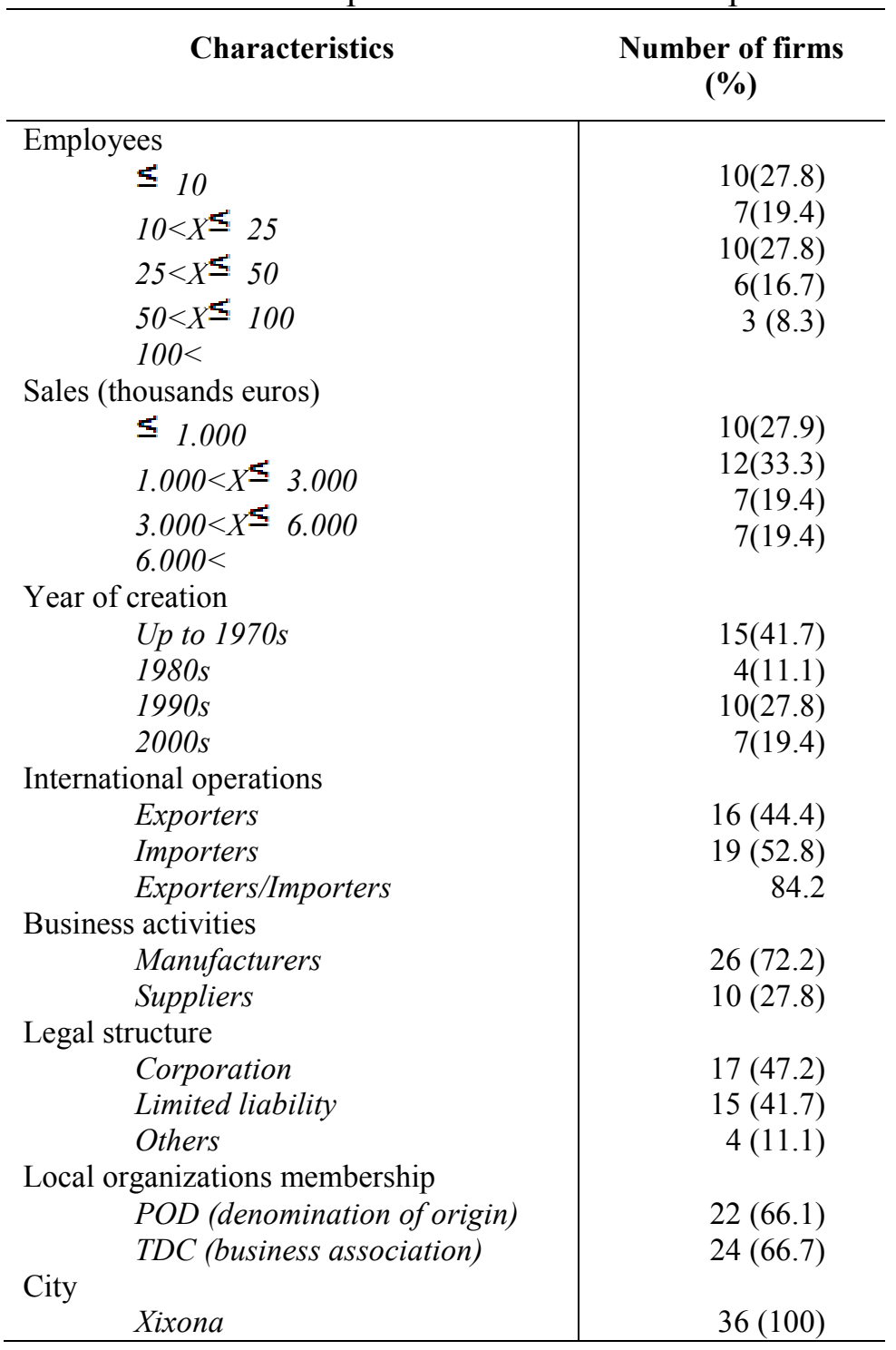

Table 2. ERGM Technical Network

\begin{tabular}{|c|c|c|c|}
\hline & Baseline model & Intermediate model & Final model \\
\hline & B (p-value) & B (p-value) & B (p-value) \\
\hline Mutual & $* * * .91$ & $* * * 1.15$ & $* * * 1.58$ \\
\hline Age & $* * *-0.04$ & ${ }^{* *} 0.05$ & ${ }^{*} 0.03$ \\
\hline Age (abs.diff) & ${ }^{* * *}-0.22$ & ${ }^{\star * \star}-0.16$ & ***-0.11 \\
\hline Absorptive capacity (in) & ${ }^{* * *} 0.43$ & ${ }^{* *} 0.39$ & 0.12 \\
\hline Absorptive capacity (out) & ${ }^{* * *}-0.82$ & $* * *-1.02$ & $* * *-0.44$ \\
\hline Supplier & 0.13 & ${ }^{*} 0.16$ & 0.10 \\
\hline Geographical proximity & & ${ }^{* \star}-0.74$ & ${ }^{* \star *}-1.62$ \\
\hline Cognitive proximity & & $* * *-0.77$ & $* * *-.57$ \\
\hline Institutional proximity & & ${ }^{*}-0.22$ & *-0.23 \\
\hline Organizational proximity & & $* * * 1.25$ & $* * * 1.30$ \\
\hline Social proximity & & ${ }^{*} 0.60$ & ${ }^{*} 0.61$ \\
\hline GWESP (2.5) & & & ${ }^{* * *} 0.21$ \\
\hline CTriple & & & ***-0.33 \\
\hline GWINDegree (0.7) & & & 4.90 \\
\hline GWOUTDegree (0.7) & & & $* * *-2.49$ \\
\hline $\mathrm{AIC}$ & 1488 & 1420 & 1339 \\
\hline $\mathrm{BIC}$ & 1519 & 1476 & 1416 \\
\hline
\end{tabular}


Table 3. QAP logit regression results

\begin{tabular}{|c|c|c|c|c|c|}
\hline & Estimate & $\operatorname{Exp}(b)$ & $\operatorname{Pr}(<=b)$ & $\operatorname{Pr}(>=b)$ & $\operatorname{Pr}(>=|b|)$ \\
\hline Intercept & -20.13 & $1.81 \mathrm{e}-09$ & 0.401 & 0.59 & 0.42 \\
\hline Institutional proximity & 1.60 & $4.94 e+00$ & 0.96 & ${ }^{* *} 0.04$ & ${ }^{*} 0.09$ \\
\hline Social proximity & -14.67 & $4.28 \mathrm{e}-07$ & 0.32 & 0.68 & 0.32 \\
\hline Cognitive proximity & 1.73 & $5.61 e+00$ & 0.96 & ${ }^{* *} 0.04$ & ${ }^{*} 0.09$ \\
\hline Geographical proximity & 14.18 & $1.44 e+06$ & 0.54 & 0.46 & 0.47 \\
\hline Age (abs. Diff) & 0.01 & $9.88 \mathrm{e}-01$ & 0.29 & 0.71 & 0.38 \\
\hline \multicolumn{6}{|l|}{ Goodness of Fit Statistics } \\
\hline \multirow{2}{*}{\multicolumn{6}{|c|}{$\begin{array}{l}\text { Null deviance: } 1746.73 \text { on } 1260 \text { degrees of freedom } \\
\text { Residual deviance: } 150.7278 \text { on } 1254 \text { degrees of freedom }\end{array}$}} \\
\hline & & & & & \\
\hline \multirow{3}{*}{\multicolumn{6}{|c|}{ 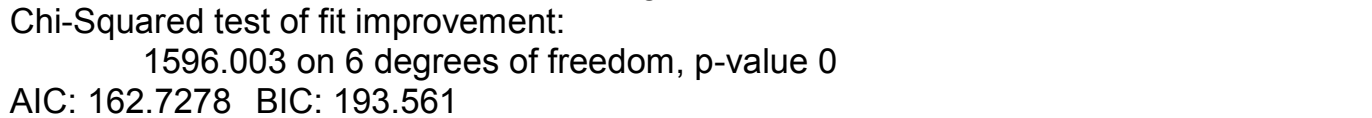 }} \\
\hline & & & & & \\
\hline & & & & & \\
\hline \multirow{2}{*}{\multicolumn{6}{|c|}{$\begin{array}{l}\text { Pseudo-R^2 Measures: } \\
\text { (Dn-Dr)/(Dn-Dr+dfn): } 0.56\end{array}$}} \\
\hline & & & & & \\
\hline \multicolumn{6}{|c|}{$\begin{array}{c}(\mathrm{Dn}-\mathrm{Dr}) / \mathrm{Dn}: 0.91 \\
\text { Total Fraction Correct: } 0.99\end{array}$} \\
\hline Significance codes: : $* * \star \prime^{\prime} 0.01^{* * *}$ & & & & & \\
\hline
\end{tabular}

